\title{
Displasia folicular em cão
}

\author{
Hair follicular dysplasia
}

\section{Mauro José Lahm Cardoso ${ }^{1}$ Sônia Regina Verde Silva Franco ${ }^{2}$ Viciany Fabris $^{3}$}

\section{RESUMO}

A displasia folicular canina é uma dermatopatia incomum caracterizada clinicamente por alopecia e alterações na qualidade da pelagem. Relata-se o caso de um cão, sem raça definida, 7 meses de idade, macho, levado à consulta por apresentar alopecia progressiva disseminada. $O$ diagnóstico anátomo-clínico da displasia folicular canina do caso ora descrito foi estabelecido pelos dados colhidos na resenha $e$ anamnese, achados do exame dermatológico e osteomuscular e confirmado pelas alterações histológicas dos fragmentos de pele biopsiados. Este artigo visa relatar um caso de displasia folicular canina e comparar com outros casos descritos na literatura, pois são esparsos as descrições na literatura brasileira.

Palavras-chave: displasia, folicular, pêlo, cão.

\section{ABSTRACT}

Canine follicular dysplasia is an uncommon skin disease of dogs characterized clinically by altered coat quality and alopecia. A case report involving a 7-month-old mongrel with diffuse alopecia is described. This case was based signalment, clinical dermatologic and osteomuscular examination and histopathology of skin byopsy. The objective of this article is to report a case of hair follicular dysplasia in a dog.

Key words: dysplasia, hair, follicle, dog.

\section{INTRODUÇÃO}

A Displasia Folicular (DF) não ligada à cor é uma condição recentemente identificada e uma variedade de raças são acometidas, com possível caráter hereditário (SCOTT et al., 1996). A displasia folicular já foi descrita nas seguintes raças Husky Siberiano (POST et al., 1988), Doberman (MILLER, 1990; HARGIS et al., 1991), Irish Water Spaniel, Buldogue Francês e Inglês, Schnauzer Miniatura; Springer Spaniel Inglês, Malamute, Pointer Alemão de pêlo curto e de pêlo de arame, Rottweiler, Chesapeake Bay retriever (GROSS et al., 1992), Retriever de Pelagem crespa, Boxer e Airedale terrier (MILLER \& DUNSTAN, 1993), Cão d'Água português (MILLER \& SCOTT, 1995). A DF é caracterizada por anormalidades anatômicas e de melanização das unidades pilossebáceas (MILLER, 1990; HARGIS et al., 1991; GROSS et al., 1992).

Os sinais precoces da displasia folicular são pelagem quebradiça, sem brilho e seca, podendo ocorrer mudanças na coloração da mesma (SCOTT et al., 1996). Há perda de pêlos primários e retenção de pêlos secundários, desenvolvimento de pêlos

\footnotetext{
${ }^{1}$ Professor de Semiologia Veterinária, Fundação Faculdades Luiz Meneghel, Bandeirantes, PR e Pós-graduando do Departamento de Reprodução Veterinária e Radiologia Animal, Faculdade de Medicina Veterinária e Zootecnia-UNESP, Botucatu-SP. Rua Doutor Yves Ribeiro, 38, Vila Maria Alice, 86360-000, Bandeirantes-PR. Telefone: 43-5428036. Fax: 43-5428008. E-mail: maurolahm@hotmail.com. Autor para correspondência.

${ }^{2}$ Professor Assistente, Doutor do Departamento de Clínica Veterinária, FMVZ-UNESP, Botucatu.

${ }^{3}$ Professor Assistente Doutor do Departamento de Patologia, FM-UNESP, Botucatu.
} 
enrolados e variados graus de alopecia. Em geral, as lesões são mais pronunciadas no tronco, mas o pescoço também pode estar envolvido, as extremidades distais dos membros são poupadas. O estabelecimento pode ser em filhotes e em adultos jovens e a progressão é lenta. As alterações secundárias mais comuns são seborréia seca e piodermatite (SCOTT et al., 1996).

Os achados histopatológicos mais comuns são hiperceratose ortoceratótica superficial e folicular, variação da atividade folicular com elevada freqüência de seqüestro catagênico, aglomerados de melanina dentro dos pêlos e bulbos pilosos, hastes pilosas fraturadas com aglomerados de melanina livre na luz dos folículos pilosos e melanófagos perifoliculares (GROSS et al., 1992). O diagnóstico diferencial inclui endocrinopatias como o hipotiroidismo, os desequilíbrios dos hormônios sexuais e o hiperadrenocorticismo, bem como as doenças displásicas (calvície padrão, displasia folicular do pêlo preto e alopecia por diluição da cor) (POST et al., 1988; MILLER, 1990; HARGIS et al., 1991; GROSS et al., 1992; SCOTT et al., 1996). O diagnóstico é estabelecido pelo exame histopatológico da pele acometida e da pele não acometida.

A displasia folicular não possui tratamento específico, o maior problema desta doença é estético, e as complicações secundárias são piodermatite e seborréia. Os retinóides sintéticos, particularmente o etritinato, podem ser úteis para o tratamento em alguns casos (SCOTT et al., 1995).

\section{RELATO DE CASO}

Um cão, sem raça definida, com sete meses de idade, macho, foi atendido no Serviço de Dermatologia do Hospital Veterinário da FMVZUNESP-Botucatu-SP, com queixa de alopecia progressiva, com ausência de prurido, a evolução era de aproximadamente dois meses. Ao exame físico, observou-se criptorquidismo bilateral, alopecia generalizada, com alguns comedões e raros pêlos na porção inferior dos membros, próximo à comissura labial, mento, face e dorso. Não havia evidência de piodermite ou seborréia. $\mathrm{O}$ animal foi submetido a exames parasitológicos do raspado de pele, cultura fúngica de pêlos e à colheita de sangue para dosagem hormonal: hormônio estimulante da tiróide (TSH), tiroxina (T4) e hormônios sexuais (17-ßestradiol, progesterona e testosterona). Os resultados destes exames estavam dentro dos padrões da normalidade para a espécie. O exame histopatológico da pele biopsada (HE) revelou dermatose atrófica com presença de grumos de melanina no bulbo piloso e hiperceratose folicular (Figura 1). O proprietário foi orientado sobre o caráter hereditário da displasia folicular e recomendou-se a orquiectomia.

\section{DISCUSSÃO}

Os achados do exame dermatológico são compatíveis com as descrições de outros autores (SCOTT et al., 1996). As alterações secundárias mais comuns são a seborréia seca e piodermatite o que não estavam presente no caso aqui relatado. A suspeita de DF deve ser considerada depois de descartada a existência de endocrinopatias (hipotiroidismo, desequilíbrios dos hormônios sexuais e hiperadrenocorticismo). As endocrinopatias podem cursar com displasia folicular, sendo esta uma alteração secundária, porém com predominância de pêlos em fase telogênica. A diferenciação da displasia folicular primária da displasia folicular secundária à alteração hormonal é baseada nos achados clínicos e laboratoriais e nas dosagens hormonais, como foi realizado neste caso. A displasia folicular deve ser diferenciada de outras doenças displásicas como calvície padrão, displasia folicular do pêlo preto e alopecia por diluição da cor. O diagnóstico diferencial destas doenças e da displasia folicular ocorre através do exame histopatológico e dos achados clínicos. A cálvice padrão acomete principalmente orelhas é ocorre com maior freqüência em cães da raça Teckel. A displasia folicular do pêlo preto acomete cães

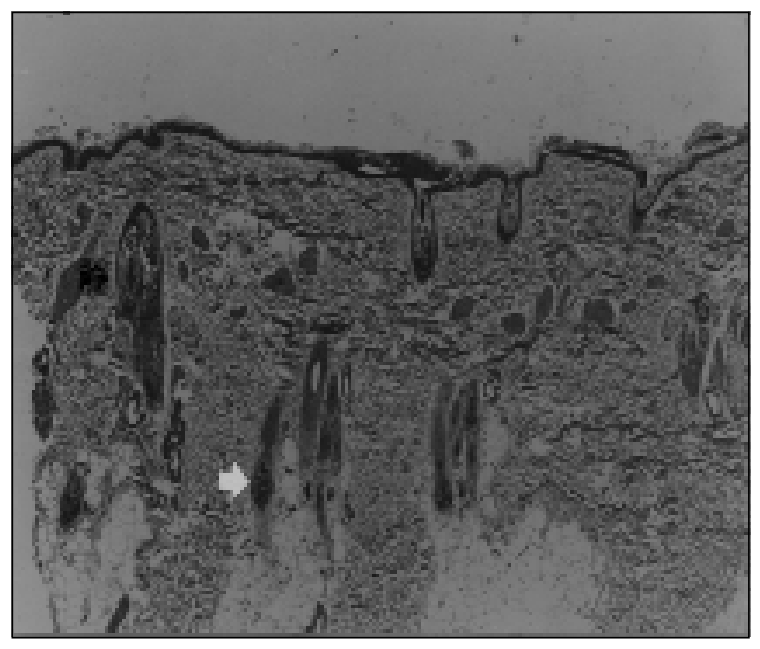

Figura 1 - Pele (Displasia Folicular) - Hiperceratose ortoceratótica, dilatação de óstios foliculares com "plugs" ceratóticos (seta preta). Grumos de melanina em bulbos pilosos geralmente em fase anágena (seta branca). Dermatose atróficas em componente inflamatório $(\mathrm{HE}-30 \mathrm{x})$. 
bicolores e somente as áreas de pêlos pretos. Na alopecia por diluição da cor, o cão começa a perder os pêlos e ocorre alteração da coloração dos pêlos remanescentes. O diagnóstico definitivo foi possível através da histopatologia, que consistia de dermatose atrófica grumos de melanina no bulbo piloso e hiperqueratose folicular. Estes achados são semelhantes aos descritos por GROSS et al. (1992). Embora, segundo esses autores, possa existir uma variação dos achados histopatológicos entre as diferentes raças. A opção pelo não tratamento deste cão deve-se aos resultados poucos encorajadores com os retinóides sintéticos, além do seu alto custo. Recomendou-se a orquiectomia do cão devido à possibilidade da hereditariedade desta doença.

\section{REFERÊNCIAS BIBLIOGRÁFICAS}

GROSS, T.L.; IHRKE, P.J.; WALDER, E.J. Veterinary dermatopathology: A macroscopic and microscopic evaluation of canine and feline skin diseases. St Louis: Mosby-Year Book, 1992. 520p.
HARGIS, A.M.; BRIGNAC, M.M.; Al-BAGDADI, F.A.K. Black hair follicular dysplasia in black and white saluki dogs: differentiation from color mutant alopecia in the Doberman pinscher by microscopic examination of hairs. Veterinary Dermatology, v.2, p.69-83, 1991.

MILLER, W.H.Jr.; SCOTT, D.W. Follicular dysplasia in adult black and red Doberman pinchers. Veterinary Dermatology, v.1, p.181-187, 1990.

MILLER, M.A.; DUNSTAN, R.W. Seazonal flank alopecia in boxers and Airdale terriers: 24 cases (1985-1992). Journal American Veterinary Medical Association, v.203, p.1567-1572, 1993.

MILLER, W.H.Jr.; SCOTT, D.W. Follicular dysplasia of the Portuguese water dog. Veterinary Dermatology, v.6, n.2, p.6774, 1995.

POST, K.; DIGNEAN, M.A.; CLARK, E.G. Hair follicle dysplasia in a Siberian husky. Journal American Animal Hospital Association, v.24, p.659-662, 1988.

SCOTT, D.W.; MILLER, W.H.Jr.; GRIFFIN, C.G. Alopecias adquiridas. In : _. Dermatologia de pequenos animais. 5.ed. Rio de Janeiro: Interlivros, 1996. Cap.10, p.671-686.

SCOTT, D.W.; MILLER, W.H.; GRIFFIN, C.G. Defeitos congênitos e hereditários. In: _____. Dermatologia de pequenos animais. 5.ed. Rio de Janeiro: Interlivros, 1996. Cap.11, p.687-752. 